\title{
Drawing Performance in Relation to Motor Skills and Zinc Level of Primary School Children in Benha City
}

\author{
A.M.Shahin ${ }^{1}$, S.M.Fayed ${ }^{2}$, R.A.Awad ${ }^{1}$ and M.A.Soliman ${ }^{1}$ \\ ${ }^{1}$ pediatrics Dept., Faculty of Medicine, Benha Univ., Benha, Egypt \\ ${ }^{2}$ Clinical pathology Dept., Faculty of Medicine, Benha Univ., Benha, Egypt \\ E-Mail: Mohamed Ali@gmail.com
}

\begin{abstract}
Zinc is a basic microelement and assumes significant jobs in the guideline and upkeep of different physiological capacities in the human body. Drawings are accepted to be general specialized instruments and are one illustration of nonverbal estimation. This examination meant to discover the connection between drawing execution, engine abilities and zinc level of elementary younger students in Benha city. This investigation was done on 400 of haphazardly picked evidently sound younger students matured from 6-12 years of age, All youngsters was exposed to the accompanying: A total a poll evaluating various variables influencing knowledge, Socio monetary level, school accomplishment, Assessment of weight and tallness (weight file), Assessment of engine advancement by the Movement Assessment Battery for Children 2 (MABC-2), Draw an individual test: Raw scores were gotten from subject's drawings, at that point changed over to IQ utilizing altered Harris scoring guide, The current fifth release of the Stanford-Binet scales (SB5) was created by Gale H. Roid and distributed in 2003 by Riverside Publishing. Furthermore, lab. appraisal of zinc level. The consequences of this investigation shows a huge positive connection between's drawing execution and engine aptitudes, and gave another proof about the significant part of Zn during development and improvement. In our examination, 116 kids (29\%) had zinc insufficiency, $\mathrm{Zn}$ inadequacy were related with diminishes anthropometric measures and helpless school execution.
\end{abstract}

Keywords: Drawing, Motor Skills, Zinc, IQ.

\section{Introduction}

Drawings are accepted to be all inclusive specialized devices and are one illustration of non verbal estimation. Portrayals of the human figure specifically are well known as a nonverbal specialized instrument [1].

One of the most punctual drawing tests was the Draw-A-Person test conceived byGoodenough, 1926 [2] to survey youngsters' imagination, mental age and visualengine scholarly development by coding highlights of their drawing of a man [3].

The movement of drawings that kids make throughout some stretch of time can show huge development and improvement, just as decide scholarly abilities and aptitudes normal for their formative level [4].

A few specialists have contended that kids' drawing aptitudes are related with socioemotional or intellectual and fine engine abilities or are related with fine engine abilities, however are in a roundabout way intervened by verbal aptitudes [5].

There is an expansion in the commitment of Fineengine Skill to drawing execution with age. In theearly phases of causing advancement kids normally pay less to notice subtleties of a drawing and, correspondingly, the drawing cycle might be less requesting as for engine execution. In later stages, when subtleties become significant, fine-engine ability may get significant in separating kids' drawing execution [6].

Zinc is a basic microelement and assumes significant jobs in the guideline and upkeep of different physiological capacities in the human body. $\mathrm{Zn}$ is likewise significant for thestructure and capacity of the sensory system. It is especially significant for youngsters during their development and advancement. Zn lack in kids can prompt inappetence, hindrance of development and advancement, and learning problems [7].

Zinc is generally perceived as a fundamental micronutrient with a reactant job in more than 100 explicit metabolic catalysts in human digestion (Pollitt, 1993). It is perhaps the most universal of all minor components. Zinc inadequacy can meddle with different organ frameworks especially when it happens during a period of fast development and advancement [8].

Writing focuses to the negative impacts of lack of healthy sustenance on intellectual exhibitions and for the most part on emotional well-being. Hunger includes protein-energy ingestion yet additionally micronutrients, for example, nutrients and minerals including zinc ( $\mathrm{Zn}$ ). $\mathrm{Zn}$ is a fundamental supplement whose inadequacy proceeds tobe an advanced wellbeing worry in both creating and created nations [9].

The point of this examination was to discover the connection between drawing execution, engine abilities and zinc level of grade younger students in Benha city.

\section{Patients and methods}

This study was carried out on 400 of randomly chosen apparently healthy school children aged from 612 years old, from first to sixth primary grades in Benha district Al-Qalibia governorate, during the period from June 2019 to june 2020. This district consisting of mixed both rural and urban cultures.

\subsection{Inclusion criteria}

- Apparently healthy primary school children aging 612 years.

- Cooperative children agreed to participate in the task. 


\subsection{Exclusion criteria}

- Children aged less than 6 and more than 12 years.

- Children had any chronic diseases which might affect child performance during the test.

- Children had any neurological abnormalities, e.g. epileptic children.

- In-cooperative children who refused to perform the test despite encouraging and offering presents and sweets, they were 45 children.

- Children of parents who refused to cooperate in filling in any part of the questionnaire or signing the consent have been excluded from the study.

This study was approved by the Ethical committee of Benha Faculty of Medicine, an informed consent was taken from the parent of the child before enrollment in the study.

All children was subjected to the following: A complete a questionnaire assessing different factors affecting intelligence, Socio economic level, school achievement, Assessment of weight and height (body mass index), Assessment of motor development by the Movement Assessment Battery for Children 2 (MABC2) [10], Draw a person test: Raw scores were obtained from subject's drawings, then converted to IQ using modified Harris scoring guide [11], The current fifth edition of the Stanford-Binet scales (SB5) was developed by Gale H. Roid and published in 2003 by

Table (1) Sociodemographic data of the study group.
Riverside Publishing [12]. And lab. assessment of zinc level.

\subsection{Statistical analysis}

The information were coded, entered and prepared on PC utilizing SPSS (variant 24). The outcomes were spoken to in even and diagrammatic structures then deciphered. Mean, standard deviation, reach, frequency, and rate were use as expressive measurements. The accompanying tests were done: Student's t-test: It is a solitary test used to altogether demonstrate the presence of any huge contrast between two gatherings for a regularly conveyed quantitative variable. One a way ANOVA ( $F$ test): A single direction investigation of fluctuation (ANOVA) is a solitary test used to all in all demonstrate the presence of any critical contrast between a few gatherings for a regularly circulated quantitative variable. Post hoc test: is utilized after one a way ANOVA ( $F$ test) or Kruskal-Wallis test to show any huge contrast between the individual gatherings. Spearman Correlation examination: It is utilized to show strength and course of relationship between one quantitative variable and ordinal subjective variable.

\section{Results}

This study was carried out on 400 of randomly chosen apparently healthy school children aged from 612 years old, from first to sixth primary grades in Benha

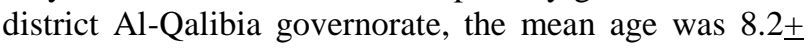
1.46 years, Table (1).

\begin{tabular}{lccc}
\hline & & $\mathbf{N}=\mathbf{4 0 0}$ & \% \\
\hline \multirow{2}{*}{ Age } & Range (years) & & $6-11$ \\
& Mean \pm S.D & & $8.2 \pm 1.46$ \\
Sex & Female & 208 & 52 \\
Residence & Male & 192 & 48 \\
& Urban & 226 & 56.5 \\
Social status & Rural & 174 & 43.5 \\
& High & 94 & 23.5 \\
Mother job & Middle & 183 & 45.75 \\
& Low & 123 & 30.75 \\
Father job & Working & 151 & 37.75 \\
& Not working & 249 & 62.25 \\
& Farmer & 65 & 16.75 \\
\hline
\end{tabular}

The mean Zinc in the studied group was $83.5 \pm 25.3 \mu \mathrm{g} / \mathrm{dl} .29 \%$ of children had zinc deficiency, $2 \%$ had excess zinc and $69 \%$ had normal zinc level Fig (1).

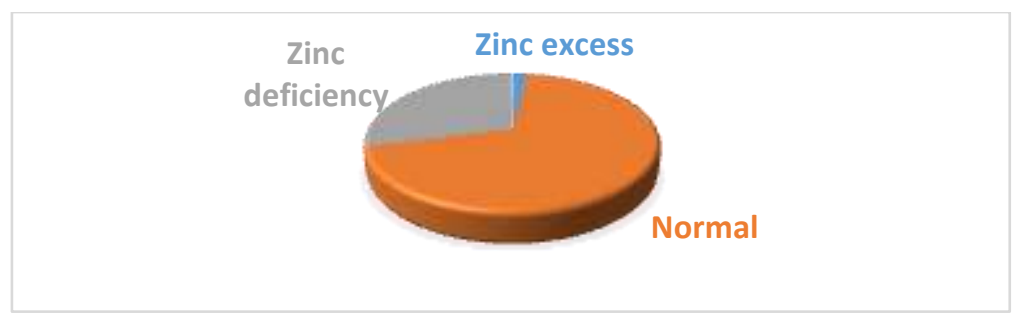

Fig (1) Classification of studied group regarding their serum zinc level. 
The mean IQ/DAP score of the studied group was $98.25 \pm 20.6,11.75 \%$ of children were classified as superior intelligence, $79.5 \%$ were average intelligence and $8.75 \%$ were borderline impaired intelligence Fig (2).

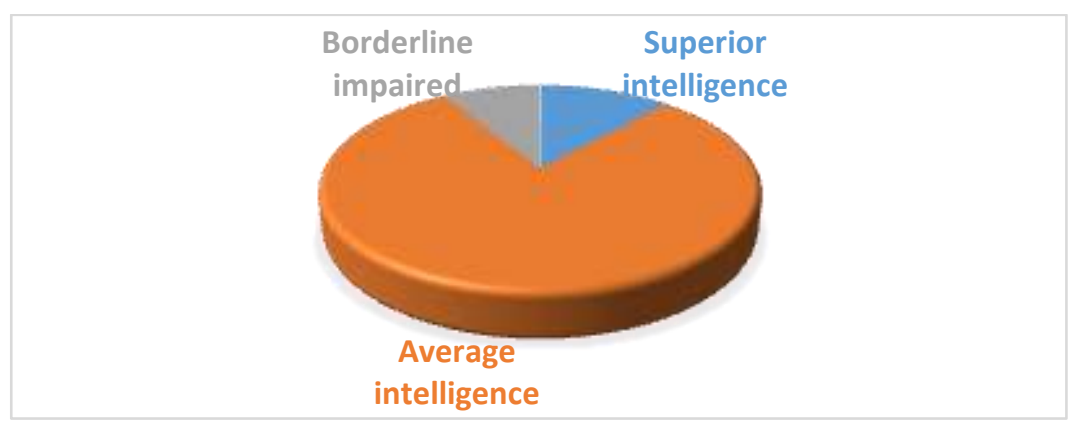

Fig (2) Classification of studied group regarding their Stanford-Binet Intelligence Scale.

Table (2) shows the motor assessment by Mabc-2 score of the studied group; the mean Manual dexterity of the studied group was $32.9 \pm 5.5$, the mean Aiming\& catching of the studied group was $19.7 \pm 3.2$, the mean score of Balance was $33.1 \pm 2.9$, and the mean total test score was $80.4 \pm 11.5$. Forty-two children $(10.5 \%)$ had scores $<15^{\text {th }}$ percentile for their age, 277 children had cores between $15-50^{\text {th }}$ percentiles and 81 children had scores above $50^{\text {th }}$ percentile, none of children had score below $5^{\text {th }}$ percentile.

Table (2) Motor assessment by The Movement Assessment Battery for Children-2 (Mabc-2) score of the studied group.

\begin{tabular}{|c|c|c|c|c|c|c|c|c|}
\hline \multirow{3}{*}{ Mabc-2 performance test } & \multirow{3}{*}{ Mean \pm SD } & \multirow{3}{*}{ Range } & \multicolumn{6}{|c|}{ Percentile } \\
\hline & & & \multicolumn{2}{|c|}{$<15^{\text {th }}$} & \multicolumn{2}{|c|}{$15^{\text {th }}-50^{\text {th }}$} & \multicolumn{2}{|c|}{$>50^{\text {th }}$} \\
\hline & & & $\mathbf{N}$ & $\%$ & $\mathbf{N}$ & $\%$ & $\mathbf{N}$ & $\%$ \\
\hline Manual dexterity & $32.9 \pm 5.5$ & $20-42$ & 43 & 10.75 & 282 & 70.5 & 75 & 18.75 \\
\hline Aiming\& catching & $19.7 \pm 3.2$ & $12-26$ & 39 & 9.75 & 272 & 68 & 89 & 22.25 \\
\hline Balance & $33.1 \pm 2.9$ & 24-39 & 44 & 11 & 275 & 68.75 & 81 & 20.25 \\
\hline Total test score & $80.4 \pm 11.5$ & $58-102$ & 42 & 10.5 & 277 & 69.25 & 81 & 20.25 \\
\hline
\end{tabular}

Mabc-2: The Movement Assessment Battery for Children-2
Fig (3) shows a comparison between zinc level in studied group regarding their school achievement; there was a statistical difference between different grades regarding their serum zinc level.

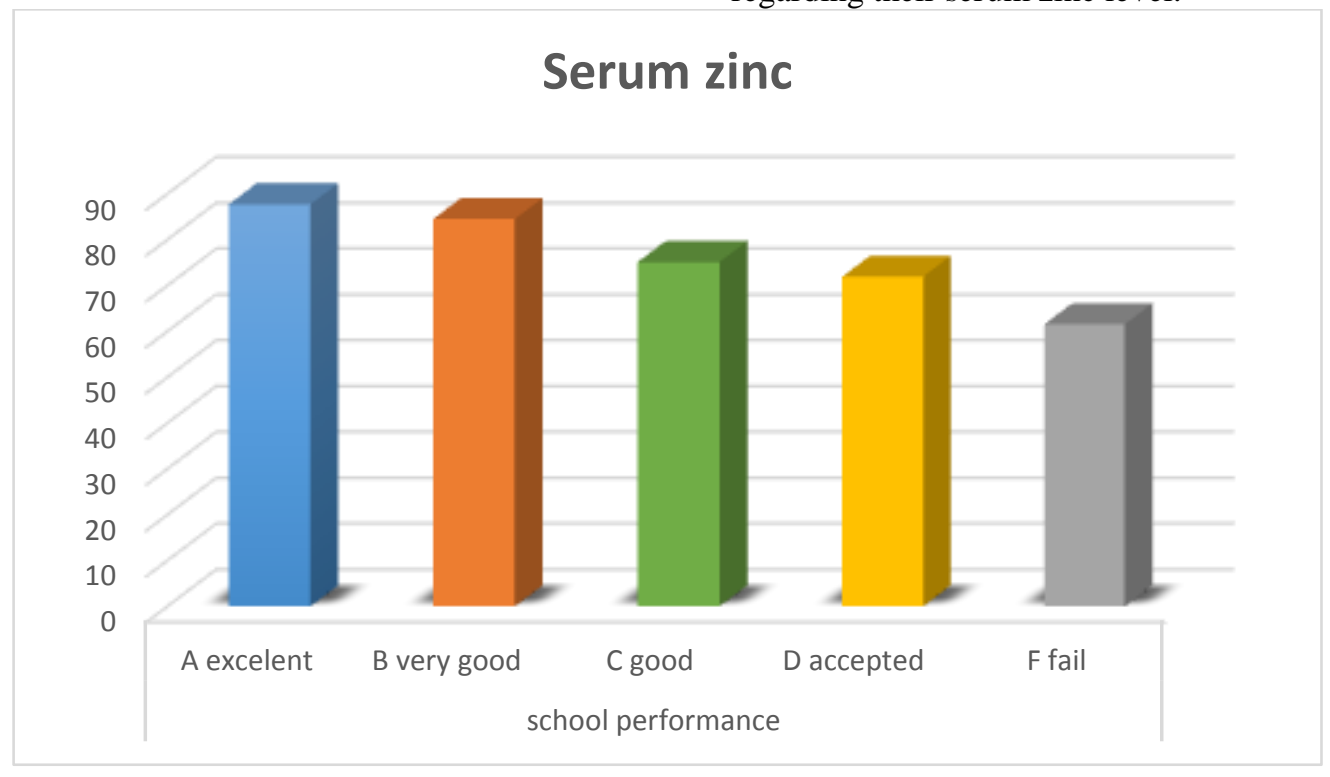

Fig (3) Comparison between zinc level in studied group regarding their school achievement. 
Table (3) shows the correlation between serum zinc level with age, anthrobometric mesures, DAP/IQ score, and Mabc2 score; there was no significant correlation between serum zinc with age or weight percentile. While there was a significant positive correlation between zinc znd (height percentile, BMI percentile, Mabc2 score, and DAP/IQ score).

Table (3) Correlation between serum zinc level with age, anthrobometric mesures, DAP/IQ score, and Mabc2 score .

\begin{tabular}{lcc}
\hline & \multicolumn{2}{c}{ Serum zinc } \\
\cline { 2 - 3 } & $\mathbf{r}$ & $\mathbf{P}$ value \\
\hline Age & 0.05 & $\mathrm{P}=0.31$ \\
Weight percentile & -0.07 & $\mathrm{P}=0.82$ \\
Height percentile & 0.338 & $\mathrm{P}<0.001 * *$ \\
BMI percentile & 0.203 & $\mathrm{P}<0.001 * *$ \\
Mabc2 score & 0.451 & $\mathrm{P}<0.001^{* *}$ \\
DAP/IQ score & 0.559 & $\mathrm{P}<0.001^{* *}$ \\
\hline
\end{tabular}

r: spearman correlation. BMI: body mass index; Mabc-2: The Movement Assessment Battery for Children-2; DAP/IQ: Draw a person/ Intelligence Quotient.

There was a significant positive correlation between DAP/IQ score and Mabc2 score, Fig (4).

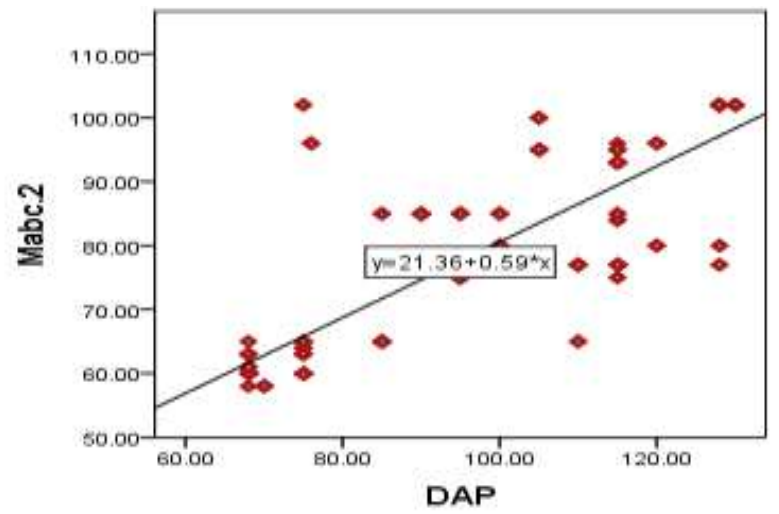

Fig (4) Correlation between DAP/IQ score and Mabc2 score.

\section{Discussion}

Zinc is a basic microelement and assumes significant parts in the guideline and upkeep of different physiological capacities in the human body. $\mathrm{Zn}$ is additionally significant for thestructure and capacity of the sensory system. It is especially significant for kids during their development and improvement. $\mathrm{Zn}$ insufficiency in kids can prompt inappetence, impediment of development and improvement, and learning problems [7].

This examination meant to discover the connection between drawing execution, engine aptitudes and zinc level of grade younger students in Benha city.

This examination was done on 400 of arbitrarily picked obviously sound younger students matured from 6-12 years of age, from 1st to 6th essential evaluations in Benha region Al-Qalibia governorate, all youngsters were exposed to a total a poll surveying various elements influencing insight, appraisal of social class, appraisal of anthropometric measures, appraisal of engine improvement by The Movement Assessment Battery for Children 2 (MABC 2), draw an individual test, estimating the IQ, and estimating serum zinc level.
This examination included 400 kids, 208 females (52\%) and 192 guys (48\%), Their mean age was 8.2+ 1.46 years. 226 kids $(56.5 \%)$ were from metropolitan zones and 174 youngsters $(43.5 \%)$ were from rustic territories, 94 kids $(23.5 \%)$ were from high social class, 183 kids $(45.75 \%)$ of center economic wellbeing, and 123 kids $(30.75 \%)$ were of low social class.

This was practically identical with [13], who led an investigation about insight of grade younger students utilizing 'draw-a-individual test' in Mansoura region, $\mathrm{Al}$ Dakahlia Governorate, the age of the examined bunch went from 6 to 12 years, Regarding home: country (51.6\%), metropolitan (48.4\%). As to status (SES): low $(13.7 \%)$, normal $(49.4 \%)$, high $(36.9 \%)$.

What's more, in [14] about factorial structure approval of the development evaluation battery for youngsters in young kids somewhere in the range of 8 and 10 years of age , $1.4 \%$ of the understudies had a place with social class $\mathrm{A} 2,8 \%$ to social class $\mathrm{B} 1,27.1 \%$ to social class $\mathrm{B} 2,35.7 \%$ to social class $\mathrm{C} 1,17.4 \%$ to social class $\mathrm{C} 2,8.6 \%$ to social class $\mathrm{C}$ and $1.4 \%$ to social class D. 
As to execution; 52 youngsters $(13 \%)$ had a fantastic evaluation at school, 163 kids $(40.75 \%)$ had a generally excellent evaluation, 122 kids $(30.5 \%)$ had a decent degree, 52 kids (13\%) had an acknowledged degree, and 11 kids $(2.75 \%)$ fizzles.

This was in concur with [13], School accomplishment was acknowledged in $6.1 \%$, great in $34.09 \%$, awesome in $52.8 \%$, and brilliant in $6.9 \%$. In [15] learn about legitimacy of the Draw a Person: a quantitative scoring framework (DAP:QSS) for clinically assessing insight, The last example comprised of 2543 members (1135 guys and 1408 females), generally of low or center SES ( the mean $29.25+11.96$, territory: $0.0-66$ ), with the mean evaluation relating to $\mathrm{C}$ on the American reviewing scale $($ mean $=7.68+1.16$, territory: $4.58-10.0)$.

As to anthropometric proportions of the contemplated gathering; the mean load of the considered gathering was $40.7+13.2$, the mean tallness was $39.5+11.3$, and the mean BMI was 39.9+ 14.9.

In [13], the mean BMI was $15.72 \pm 2.69$, conveyed as underweight $(18.2 \%)$, ordinary $(76.7 \%)$, overweight (3\%), and hefty $(1.8 \%)$.

Concerning engine evaluation by Mabc- 2 score of the examined gathering; the mean Manual finesse of the considered gathering was $32.9 \pm 5.5$, the mean Aiming\& getting of the contemplated bunch was $19.7 \pm 3.2$, the mean score of Balance was $33.1 \pm 2.9$, and the mean all out grade was $80.4 \pm 11.5$. 42 kids $(10.5 \%)$ had scores $<15$ th percentile for their age, 277 youngsters had centers between 15-50th percentiles and 81 kids had scores above 50th percentile, none of kids had score beneath fifth percentile.

The MABC, and now the MABC-2, is quite possibly the most generally utilized pediatric engine debilitation evaluations, the MABC-2 is enthusiastically suggested for use by specialists. It can assume a significant part in the evaluation of and mediation getting ready for kids and teenagers [16].

[14] assessed the factorial association of the MABC2 for the age bunch 8-10 years from the point of view of old style and present day psychometric hypothesis, a gathering of 350 younger students in the city of Manaus (AM, Brazil) was assessed. The factorial structure of the MABC-2 and another factorial structure with four elements were tried. great confirmations of legitimacy were delivered, in light of the inner structure of the MABC-2 proposed by the first creators, affirming its capacity to recognize messes in the advancement of coordination.

In [17], Cognitive level and formative coordination problem: concentrate with younger students matured 7 to 10 years of age, Of the 402 youngsters assessed, 35 $(8,7 \%)$ had Mabc-2 scores < 15 th percentile for their age.

With respect to/IQ score in the contemplated gathering; the mean score of the considered gathering was $98.25 \pm 20.6,52$ youngsters $(11.75 \%)$ of kids were delegated prevalent knowledge, 314 kids (79.5\%) were normal insight and 35 kids $(8.75 \%)$ were fringe impeded knowledge.
Also in [13], the dispersion of IQ levels among the examined test indicated that kids with unrivaled knowledge comprising $10.9 \%$ of the contemplated test, high level of normal insight gathering $(69.2 \%)$, marginal scholarly capacity $(17.3 \%)$, and kids with less than ideal knowledge $(2.7 \%$, with a mean IQ of $97.91 \pm 9.92$. While in [15], the mean DAP:QSS absolute score was $127.75+24.91,65$ youngsters were inadequate, 117 kids were fringe, 361 kids were low normal, 1332 kids were normal, 468 kids were high normal, 176 kids were prevalent, and 24 kids were unrivaled.

The appraisal of knowledge has a long disputable history. However, as of late, one zone that has gotten more extreme spotlight on the investigation of cognizance has been the evaluation of neuropsychological working in youngsters and youths [18]

In this investigation, the mean was $83.5 \pm 25.3 \mu \mathrm{g} / \mathrm{dl}$. 116 youngsters $(29 \%)$ had zinc inadequacy, 8 kids $(2 \%)$ had overabundance zinc and 278 kids (69\%) had typical zinc level.

The pervasiveness and weight of zinc inadequacy was very extraordinary around the world, the commonness of zinc insufficiency in Iran was about $7.9 \%$ [19]. another investigation in Iran demonstrated a predominance of $28.1 \%$ [20]. Higher predominance was seen in [21], concentrate in North-Okkalapa Township, demonstrated high commonness of zinc lack $(69.6 \%)$ and low mean serum zinc level $(8.1 \pm 4.4 \mu \mathrm{mol} / \mathrm{l})$ in grade younger students. furthermore, in [22], An aggregate of 55 kids $(87.3 \%)$ in Sunsari and $52(83.9 \%)$ in Dhankuta had zinc inadequacy, We thought about that the diverse nearby nourishments and dietary propensities may have caused these provincial contrasts.

In this investigation, there was no huge relationship between's serum zinc and (age or weight percentile). A few agents have demonstrated propensity for serum $\mathrm{Zn}$ to increment with age [23], while others indicated no adjustment in serum $\mathrm{Zn}$ with expanding age [20].

Mama et al. [23] in China demonstrated that extents of insufficient $\mathrm{Zn}$ admissions, were $15.9 \%$ and $12.9 \%$ in age bunches 4-6 years and 7-10 years old. Expanded prerequisites of $\mathrm{Zn}$ in the developing young kids might be because of the necessity of pubertal development spray, hormonal impacts and existing together micronutrient insufficiencies. Connections of $\mathrm{Zn} \mathrm{lack,}$ related with age can be clarified based on bewildering impacts of pubertal status and leather expert stage, requirements on development because of ongoing disease and the conjunction of other development restricting micronutrient inadequacies, for example, iodine, as portrayed in a past report [24].

In this examination, there was a critical positive relationship among's zinc and (tallness percentile, BMI percentile, Mabc2 score, and DAP/IQ score). While in [19], There was no relationship among serum zinc level and age, sex, tallness, weight or BMI, yet gentle squandering (weight for age) and mellow hindering (stature for age) were essentially more predominant 
among zinc insufficient kids contrasted with youngsters with typical or elevated level of zinc.

In Eh-Shazly et al. [25], there was a measurably huge positive relationship of serum zinc with both body weight and BMI, however no genuinely critical connection of serum zinc with age or stature among the examination bunch after zinc supplementation.

In this investigation, there was a huge positive relationship between's DAP/IQ score and Mabc2 score $(\mathrm{r}=0.824, \mathrm{p}<0.001)$. This was in concur with [17], there was a critical affiliation $(\mathrm{p}=0,009)$ between the worldwide percentile in MABC-2 and the IQ acquired by Raven scale. Essentially, [26] found a positive relationship between's a joined proportion of intellectual and engine improvement and drawing capacity, Also [27] recommend DAP:IQ scores are a hearty and solid pointer of fine engine capacity yet not psychological capacity.

\section{Conclusion}

The aftereffects of this examination shows a critical positive relationship between's drawing execution and engine aptitudes, and gave another proof about the significant part of $\mathrm{Zn}$ during development and advancement. In our investigation, 116 youngsters (29\%) had zinc lack, $\mathrm{Zn}$ inadequacy were related with diminishes anthropometric measures and helpless school execution.

\section{References}

[1] T. Grebelsky-Lichtman, "Children's verbal and nonverbal congruent and incongruent communication during parent-child interactions," Hum. Commun. Res., Vol.40, PP.415-441, 2014.

[2] F. L. Goodenough, "Measurement of intelligence by drawings.," Vol.1926, pp 1-15, 1926.

[3] S. Raja and B. M. John, "An Assessment of Drawing Age in Pre-School Children Using'Draw-A-Man'Test," J. Nepal Paediatr. Soc., Vol.34, PP.14-17, 2014.

[4] P. Kotroni, F. Bonoti, and S. Mavropoulou, "Children with autism can express social emotions in their drawings," Int. J. Dev. Disabil., Vol.65, PP.248-256, 2019.

[5] S. Suggate, H. Stoeger, and U. Fischer, "Fingerbased numerical skills link fine motor skills to numerical development in preschoolers," Percept. Mot. Skills, Vol.124, PP.1085-1106, 2017.

[6] A. Simpson, R. Al Ruwaili, R. Jolley, H. Leonard, N. Geeraert, and K. J. Riggs, "Fine motor control underlies the association between response inhibition and drawing skill in early development," Child Dev., Vol.90, PP.911-923, 2019.

[7] Y. Wu, J. Sun, M. Wang, G. Yu, L. Yu, and C. Wang, "The relationship of children's intelligence quotient and blood lead and zinc levels: a metaanalysis and system review," Biol. Trace Elem. Res., Vol.182, PP.185-195, 2018.
[8] M. A. Al Mamun and R. B. A. Ghani, "The role of iron and zinc in cognitive development of children," Asian J. Med. Biol. Res., Vol.3, PP.145-151, 2017.

[9] V. Papadopol, E. Tuchendria, and I. Palamaru, "Zinc levels, cognitive and personality features in children with different socioeconomic backgrounds," Eur. J. Psychol., Vol.6, PP.82-101, 2010.

[10] S. E. Henderson, D. A. Sugden, and A. L. Barnett, "Movement assessment battery for childrensecond edition." Harcourt Assessment London, England, Vol.2007, PP.593-650, 2007.

[11] D.B. Harris, Children's drawings as measures of intellectual maturity: Revision of Goodenough draw-a-man test. Vol.1963, PP.343-401, 1963.

[12] G. F. Madaus, C. A. Lynch, and P. S. Lynch, "Stanford-binet intelligence scales," Educ. Meas. Issues Pract., Vol.11, PP.5-11, 2008.

[13] A. M. El-Shafie, D. M. El Lahony, Z. O. Abd El Latif, and M. O. A. Khalil, "Draw-a-person test as a tool for intelligence screening in primary school children," Menoufia Med. J., Vol.32, p. 329, 2019.

[14] J. O. L. dos Santos, N. S. Formiga, G. F. de Melo, M. H. da S. Ramalho, and F. L. Cardoso, "Factorial Structure Validation of the Movement Assessment Battery for Children in School-Age Children Between 8 and 10 Years Old," Paid. (Ribeirão Preto), Vol.27, PP.348-355, 2017.

[15] A. Troncone, A. Chianese, A. Di Leva, M. Grasso, and C. Cascella, "Validity of the Draw a Person: A Quantitative Scoring System (DAP: QSS) for Clinically Evaluating Intelligence," Child Psychiatry Hum. Dev., Vol.21, PP.1-11, 2020.

[16] T. Brown, "Movement Assessment Battery for Children: (MABC-2)," in Encyclopedia of autism spectrum disorders, Springer, Vol.2018, PP.1-20, 2008.

[17] M. M. Barbacena, A. M. V. N. Van Petten, D. L. Ferreira, and L. de C. Magalhães, "Cognitive level and developmental coordination disorder: study with schoolchildren aged 7 to 10 years old," Cad. Bras. Ter. Ocup., Vol.27, PP.534-544, 2019.

[18] L.Rinaldi, A. Karmiloff-Smith, "Intelligence as a developing function: A neuroconstructivist approach,” J. Intell., Vol.5, p. 18, 2017.

[19] S.M. Dehghani, P. Katibeh, M. Haghighat, H. Moravej, and S. Asadi, "Prevalence of zinc deficiency in 3-18 years old children in ShirazIran," Iran. Red Crescent Med. J., Vol.13, p. 4, 2011.

[20] A.Fesharakinia, A. Zarban, and G. H. R. SHARIFZADEH, "Prevalence of zinc deficiency in elementary school children of South Khorasan Province (East Iran)," Vol.2, PP.34-45, 2009.

[21] K. N. Thein et al., "Myanmar Health Sciences Research Journal, Vol.29, PP.1-19, 2017."

[22] A. K. Nepal, B. Gelal, K. Mehta, M. Lamsal, P. K. Pokharel, and N. Baral, "Plasma zinc levels, anthropometric and socio-demographic 
characteristics of school children in eastern Nepal,” BMC Res. Notes, Vol.7, PP.1-6, 2014.

[23] G. Ma et al., "Iron and zinc deficiencies in China: what is a feasible and cost-effective strategy?," Public Health Nutr., Vol.11, PP.632-638, 2008.

[24] R.A. Thurlow et al., "Risk of zinc, iodine and other micronutrient deficiencies among school children in North East Thailand," Eur. J. Clin. Nutr., Vol.60, PP.623-632, 2006.

[25] A. N. El-Shazly, S. A. E.-H. Ibrahim, G. M. ElMashad, J. H. Sabry, and N. S. Sherbini, "Effect of zinc supplementation on body mass index and serum levels of zinc and leptin in pediatric hemodialysis patients," Int. J. Nephrol. Renovasc. Dis., Vol.8, p. 159, 2015.

[26] S.Schepers, M. Deković, M. Feltzer, M. de Kleine, and A. van Baar, "Drawings of very preterm-born children at 5 years of age: a first impression of cognitive and motor development?," Eur. J. Pediatr., Vol.171, PP.43-50, 2012.

[27] G.L.Rehrig, "Drawing comparisons between drawing performance and developmental assessments." Rutgers University-Graduate School-New Brunswick, Vol.2015, PP.19-53, 2015. 